\title{
FITOSSOCIOLOGIA E DIVERSIDADE DE ESPÉCIES ARBÓREAS EM CABRUCA (MATA ATLÂNTICA RALEADA SOBRE PLANTAÇÃo DE CACAU) NA REGIÃo SUL DA BAHIA, BRASIL
}

\author{
Regina Helena Rosa Sambuichi ${ }^{1}$
}

Recebido em 21/09/99. Aceito em 20/09/01.

\begin{abstract}
RESUMO - (Fitossociologia e diversidade de espécies arbóreas em cabruca (mata atlântica raleada sobre plantação de cacau) na Região Sul da Bahia, Brasil). Na região sul da Bahia a maior parte das lavouras de cacau foi implantada sob a mata nativa raleada, em um sistema conhecido como cabruca. Em uma área de 2,6 ha de cabruca, foi realizado o levantamento fitossociológico das árvores com DAP $5 \geq \mathrm{cm}$ utilizadas no sombreamento do cacau, objetivando caracterizar a diversidade de espécies, composição e estrutura dessa comunidade. Foram encontrados nessa área 138 indivíduos, pertencentes a 41 espécies e 25 famílias, com $20,0 \mathrm{~m}^{2}$ de área basal e $471,5 \mathrm{~m}^{3}$ de volume cilíndrico. As espécies que apresentaram maiores porcentagens de Importância de Wisconsin foram: Spondias lutea L. (9,7\%), Pithecelobium polycephalum Benth. (9,4\%), Inga affinis Benth. (7,0\%) e Cedrela odorata L. (7,0\%). O índice de diversidade de Shannon foi 3,35 e o de Brillouin 2,96. O diâmetro à altura do peito (DAP) variou de $5,0 \mathrm{~cm}$ a $126,8 \mathrm{~cm}$. A altura variou de $4,5 \mathrm{~m}$ a $39,4 \mathrm{~m}$, com média de $15,9 \mathrm{~m}$. Foram encontradas convivendo na área espécies nativas (pioneiras, de florestas secundárias e de florestas primárias) e exóticas. Comparações feitas com outros trabalhos em áreas de cabruca mostram que estas apresentam uma alta diversidade de espécies arbóreas e são heterogêneas em estrutura, o que é influenciado pelo histórico de implantação e manejo das áreas.
\end{abstract}

Palavras-chave - mata atlântica, cabruca, diversidade de espécies, fitossociologia

ABSTRACT - (Phytosociology and diversity of tree species in a cabruca (atlantic rainforest above cocoa plantation) in south Bahia Region, Brazil). In southern Bahia most of the cocoa plantations was established under the Atlantic Rainforest after thinning, in a system called cabruca. The shading tree community with $\mathrm{DBH} \geq 5,0 \mathrm{~cm}$ in 2.6 ha of cabruca was studied. A total of 138 individuals was found, belonging to 41 species and 25 families, with a basal area of $20.0 \mathrm{~m}^{2}$ and a cylindrical volume of $471.5 \mathrm{~m}^{3}$. The species with highest Wisconsin index were Spondias lutea L. (9.7\%), Pithecelobium polycephalum Benth. (9.4\%), Inga affinis Benth. (7.0\%) and Cedrela odorata L. (7.0\%). Shannon diversity index was 3.35 and Brillouin diversity index was 2.96. The diameter at breast height $(\mathrm{DBH})$ was in the range of $5.0 \mathrm{~cm}$ to $126.8 \mathrm{~cm}$. The height was in the range of $4.5 \mathrm{~m}$ to $39.4 \mathrm{~m}$, with a mean of $5.9 \mathrm{~m}$. Native species (pioneer, secondary and climax species) and exotic species were found in the area. The cabrucas had high tree diversity and were heterogeneous in structure reflecting the influence of the management history of these areas.

Key words - atlantic rainforest, cabruca, species diversity, phytosociology

\footnotetext{
${ }^{1}$ Profa do Dep. de Ciências Biológicas, Universidade Estadual de Santa Cruz-UESC, rod Ilhéus-Itabuna, km 16, IlhéusBA, CEP 45.650-000.
} 


\section{Introdução}

A mata atlântica da região sul da Bahia é uma floresta tropical úmida muito rica em espécies e com alto grau de endemismo (Mori et al. 1983: Thomas et al. 1998: Thomas et al. in press). Estima-se que essa floresta esteja atualmente reduzida a menos de $7 \%$ de sua cobertura original (Alger \& Caldas 1996). Um fator que vem contribuindo para a conservação de parte da biodiversidade dessa floresta é o cultivo tradicional do cacau sob a mata raleada (Rice \& Greenberg 2000).

Nesse sistema de plantio, conhecido como "cabruca", conserva-se apenas uma parte selecionada das árvores da mata nativa, substituindo-se o sub-bosque por cacaueiros. Graças às cabrucas, pode-se ainda encontrar no sul da Bahia uma das maiores concentrações de árvores nativas do leste do Brasil (Vinha \& Silva 1982). Um estudo realizado com fauna, mostrou que a diversidade de aves e mamíferos em cabruca é menor do que em mata primária, porém, maior do que em áreas onde o cacau é plantado sob bananeiras e árvores exóticas (Alves 1990).

Estima-se que $70 \%$ dos $6.800 \mathrm{~km}^{2}$ de plantações de cacau ainda seja cabruca (Franco et al. 1994). Alger \& Caldas (1996) mostraram que, nas grandes fazendas de cacau, $86 \%$ da área ainda está sob esse sistema. Esses dados, quando comparados com os $863 \mathrm{~km}^{2}$ de mata nativa estimados em 1991 (Por 1992) mostram o grande potencial das cabrucas para conservação na região.

Apesar da importância desse sistema de plantio, poucos estudos foram realizados até o momento sobre a vegetação nativa conservada nas cabrucas. Alvim \& Pereira (1965) fizeram um levantamento das árvores em áreas de cabruca da região e estimaram uma densidade média de 76 árvores de sombra por hectare, elaborando uma lista com as principais espécies encontradas e suas respectivas densidades. Es- ses dados, porém, já não correspondem à realidade, pois a partir desse trabalho foi iniciada uma campanha para a redução do número de árvores para 25 a 35 indivíduos por hectare visando aumentar a produtividade dos cacaueiros (Alvim 1966). Hummel (1995) fez o levantamento da vegetação, incluindo árvores, arbustos, lianas, epífitas e herbáceas, de duas áreas de cabruca localizadas no Município de Ilhéus, BA. Ele encontrou uma alta diversidade, mas também um alto grau de descaracterização do componente arbóreo em relação à mata nativa, pois as espécies exóticas em conjunto apresentaram mais de 50\% de importância na área.

O presente trabalho consiste em um levantamento das árvores utilizadas no sombreamento do cacau em uma área de cabruca antiga, avaliando a fitossociologia e a diversidade de espécies na área. Objetivou-se, através de comparações com outros trabalhos já realizados em cabruca, caracterizar a diversidade de espécies, composição florística e estrutura desse tipo de comunidade arbórea.

\section{Material e Métodos}

Foi estudada uma área de 2,6 hectares de cacau em sistema de cabruca situada a $14^{\circ} 36^{\prime}$ $52,3^{\prime \prime} \mathrm{S}$ e $39^{\circ} 15^{\prime} 54,0^{\prime \prime} \mathrm{W}$, próxima à sede da Fazenda Novo Horizonte, km 30 da rodovia Ilhéus-Uruçuca, Município de Ilhéus, BA. O solo da área é Podzólico Eutrófico, pouco profundo, com alguns afloramentos de rocha. $\mathrm{O}$ clima da região é tropical quente e úmido, tipo Af de Köppen, com umidade relativa média de $89-90 \%$ e temperatura média de $24-25^{\circ} \mathrm{C}$.

Um mapa da fazenda feito há mais de 50 anos mostra que a área de estudo já era utilizada para o plantio de cacau, portanto, o raleamento da mata nativa para a implantação do cultivo foi anterior a essa época (provavelmente mais de 100 anos). No período em que foi realizada a coleta dos dados (setembro a novembro de 1997), a lavoura da área estudada encon- 
trava-se em estado de semi-abandono devido à crise econômica que vem se abatendo sobre a cultura do cacau na região. Tratos culturais tradicionalmente utilizados como adubação, calagem e aplicação de inseticidas não eram realizados na área há mais de dez anos. A poda dos cacaueiros e o corte da vegetação rasteira (roçagem), que normalmente são realizados pelo menos uma vez por ano, não eram realizados há mais de dois anos.

O projeto original previa uma área amostral retangular única de 3 ha, subdividida em 60 parcelas contíguas. Porém, devido ao formato irregular da área de cabruca estudada, cortada por um riacho e fragmentos de capoeira e mata, o desenho da área amostral precisou ser modificado e o tamanho reduzido para 2,6 ha, subdividido em 52 parcelas contíguas de $20 \mathrm{~m}$ x $25 \mathrm{~m}$ (Fig. 1). Foram incluídos no censo todos os indivíduos arbóreos com $5 \mathrm{~cm}$ ou mais de diâmetro do tronco à altura do peito (DAP), excluindo-se os cacaueiros (Theobroma cacao L.). A altura foi medida até a parte mais alta da copa com auxílio de uma trena e um clinômetro, utilizando o método do triângulo retângulo com ângulo de $45^{\circ}$.

As espécies estranguladoras, quando ocorreram como hemiepífitas (apoiadas sobre a ár-

Figura 1. Mapa da área estudada.

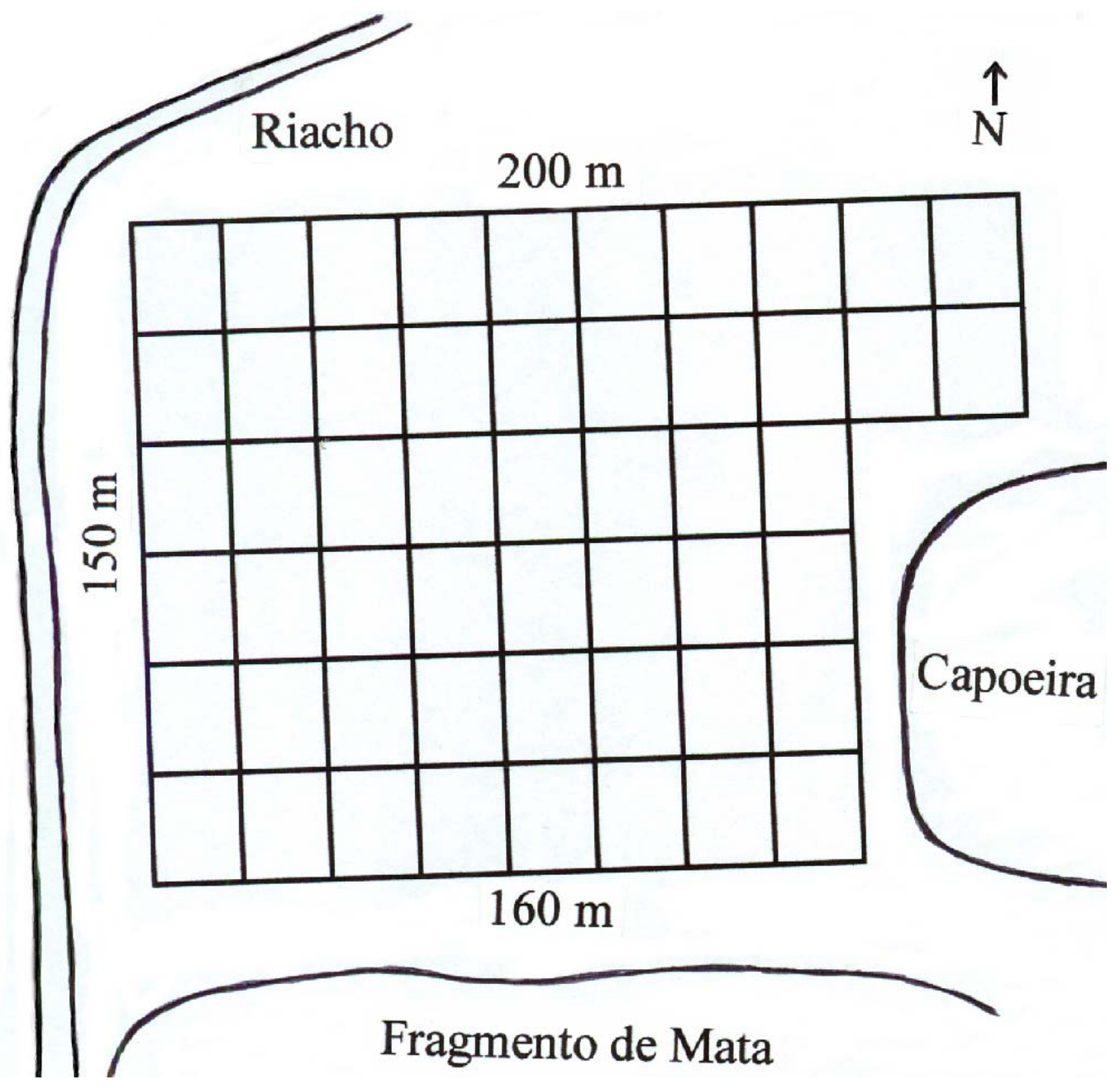


vore hospedeira, mas enraizadas no chão), foram incluídas na contagem se no mínimo uma das raízes aéreas apresentava $5 \mathrm{~cm}$ ou mais de DAP, sendo a sua área basal a soma das áreas basais de todas as raízes que atingiram esse limite. As exsicatas obtidas foram depositadas no Herbário da Universidade Estadual de Santa Cruz (UESC), Ilhéus BA.

Foram calculados, para cada espécie, o número de indivíduos, a frequiência, a área basal e o volume cilíndrico (área basal x altura) (GreigSmith 1983). Foi calculada a Porcentagem de Importância de Wisconsin, sendo a média dos valores relativos de densidade, frequência e área basal. Este índice foi preferido em relação ao Índice de Valor de Importância (IVI), por apresentar os resultados em porcentagem.

Calculou-se também o número de indivíduos, número de espécies e a área basal total por família botânica. Para estimar a diversidade de espécies foram calculados seguintes índices: Shannon $H^{\prime}=-\sum\left(p_{i} \times \ln p_{i}\right)$, calculado para $p_{i}=$ densidade relativa e $p_{i}=\%$ de importância; Brillouin $\mathrm{H}=\left(\ln \left(\mathrm{N} ! / \mathrm{n}_{1} ! \mathrm{n}_{2} ! \mathrm{n}_{3} ! \ldots . \mathrm{n}_{\mathrm{s}} !\right)\right) / \mathrm{N}$ onde: $\mathrm{N}=$ número total de indivíduos, $\mathrm{n}_{\mathrm{i}}=$ número de indivíduos de cada espécie e $\mathrm{s}=$ número de espécies.

Informações sobre o histórico de manejo da área foram obtidas através de conversas com o proprietário e os trabalhadores rurais da fazenda.

Os resultados obtidos no presente trabalho foram comparados com o levantamento, feito por Hummel (1995), na fazenda Serra Grande, Ilhéus BA $\left(14^{\circ} 45^{\prime} 18^{\prime \prime} \mathrm{S}\right.$ e $\left.39^{\circ} 14^{\prime} 1,5^{\prime \prime} \mathrm{W}\right)$. O autor realizou o levantamento de todas as árvores de $5 \mathrm{~cm}$ ou mais de DAP em 2,6 ha de cabruca. A área foi subdividida em 4 transectos de $30 \mathrm{~m}$ de largura, de $8500 \mathrm{~m}^{2}, 6250 \mathrm{~m}^{2}, 6000$ $\mathrm{m}^{2}$ e $5250 \mathrm{~m}^{2}$ cada um. A área também encontrava-se sem aplicação de inseticidas e fertilizantes na época do estudo.

O trabalho não traz informações sobre o histórico de implantação da área, mas, pelas características e localização da mesma, podese supor que seja uma área também de implantação antiga. As distribuições de indivíduos por classe de diâmetro e de altura obtidas no presente trabalho foram comparadas com as do trabalho de Hummel (1995) através do teste Kolmogorov-Smirnov que compara a distribuição de frequências de duas amostras independentes (Siegel 1975). A similaridade florística entre as áreas foi comparada através dos índices de Sorensen (qualitativo) e Bray-Curtis (quantitativo) (Mueller-Dumbois \& Ellenberg 1974):

\section{Resultados e Discussão}

Fitossociologia e estrutura da comunidade - foi encontrado na área um total de 138 indivíduos, pertencentes a 41 espécies e 25 famílias. A área basal total foi de $20,03 \mathrm{~m}^{2}$ e o volume cilíndrico $471,55 \mathrm{~m}^{3}$. A espécie que apresentou maior importância $(9,7 \%)$ e maior área basal $\left(2,77 \mathrm{~m}^{2}\right)$ foi Spondias lutea. A maior densidade relativa $(12,3 \%)$ e frequiência $(28,9 \%)$ foi da espécie Pithecelobium polycephalum. A espécie que apresentou maior volume cilíndrico $\left(69,96 \mathrm{~m}^{3}\right)$ foi Cedrela odorata (Tab. 1). A família Mimosaceae apresentou o maior número de indivíduos (29), enquanto a família Moraceae apresentou o maior número de espécies (5) e a família Anacardiaceae apresentou a maior área basal $\left(3,19 \mathrm{~m}^{2}\right)$ (Tab. 2).

Foram incluídos na contagem três indivíduos na forma de hemiepífita, pertencentes às espécies Ficus gomelleira, Ficus clusiifolia e Coussapoa microcarpa. A área estudada apresentou uma baixa densidade de indivíduos, mas uma alta quantidade de espécies e famílias em relação à quantidade de indivíduos contados. Um padrão semelhante ocorreu na área estudada por Hummel (1995), também com 2,6 ha, onde foram encontrados 145 indivíduos, pertencentes a 40 espécies e 21 famílias.

Com relação à biometria das árvores, o diâmetro máximo foi $126,8 \mathrm{~cm}$, sendo que $39,1 \%$ dos troncos apresentou diâmetro inferior a 20,0 


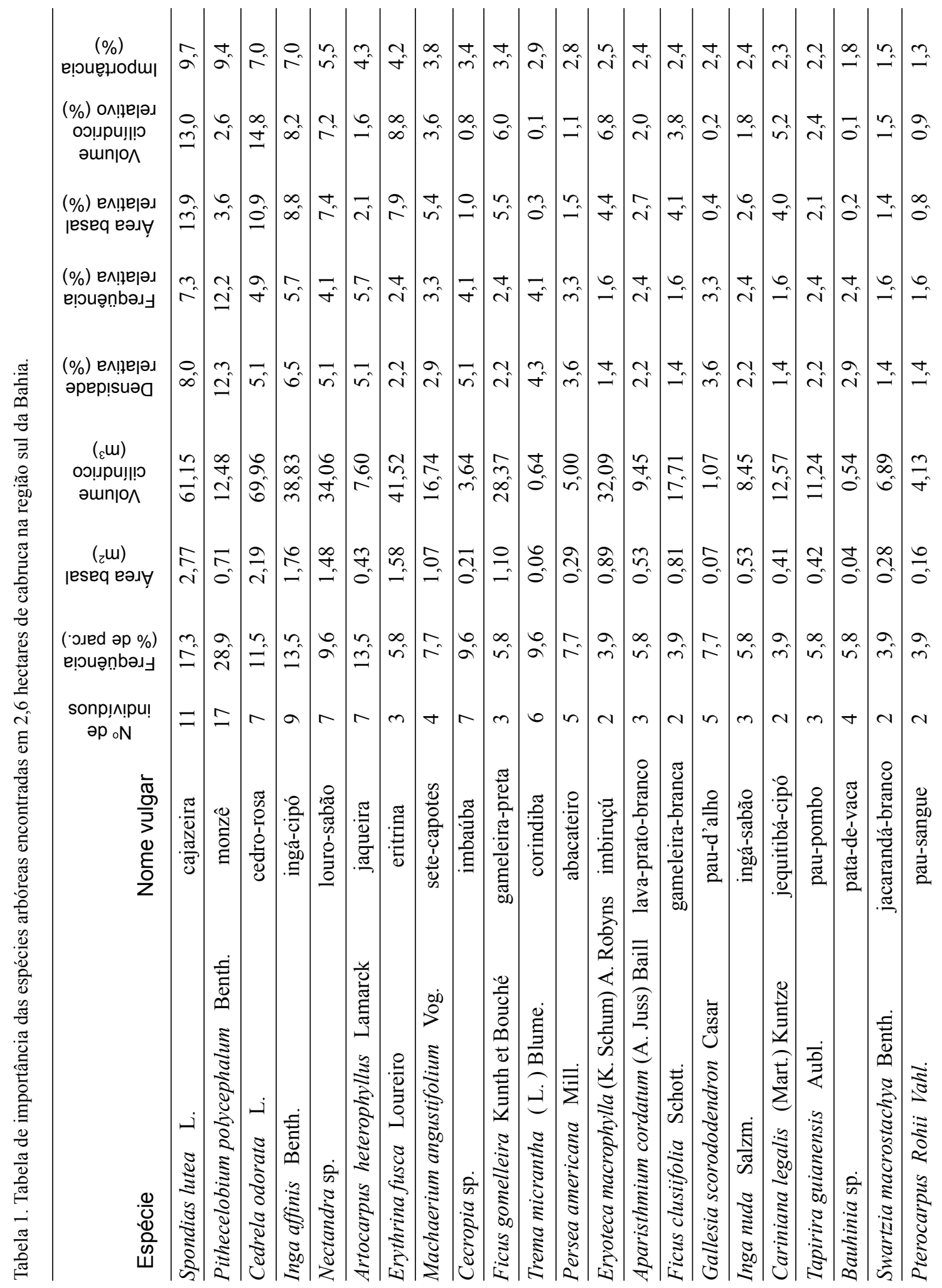




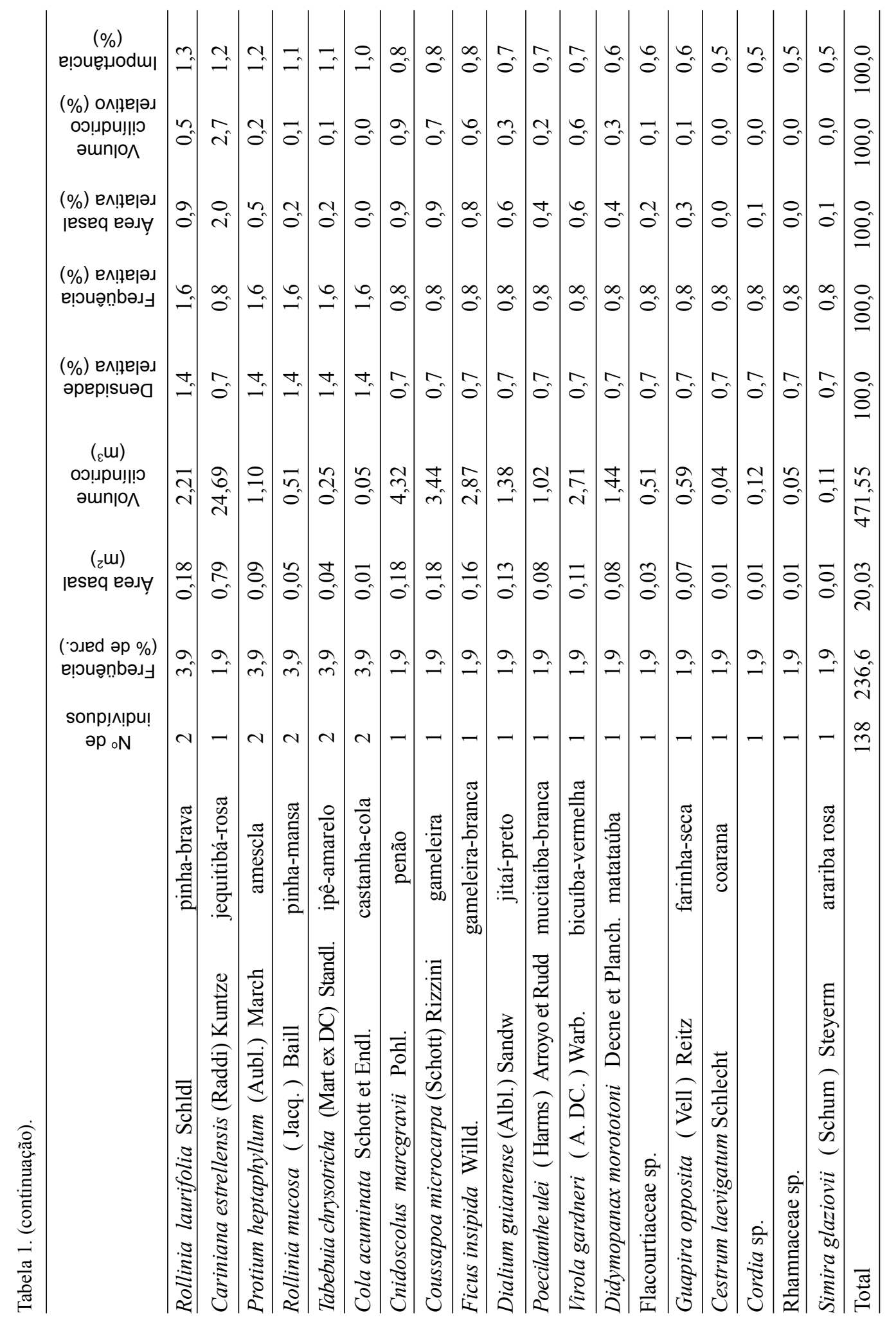


Tabela 2. Número de indivíduos, número de espécies e área basal de árvores por família botânica encontrada em 2,6 hectares de cabruca na região sul da Bahia.

\begin{tabular}{|c|c|c|c|}
\hline Família & $\begin{array}{c}\mathrm{N}^{\mathrm{o}} \mathrm{de} \\
\text { indivíduos }\end{array}$ & $\begin{array}{c}\mathrm{N}^{\circ} \mathrm{de} \\
\text { espécies }\end{array}$ & $\begin{array}{c}\text { Área } \\
\text { Basal }\left(\mathrm{m}^{2}\right)\end{array}$ \\
\hline Anacardiaceae & 14 & 2 & 3,19 \\
\hline Annonaceae & 4 & 2 & 0,23 \\
\hline Araliaceae & 1 & 1 & 0,08 \\
\hline Bignoniaceae & 2 & 1 & 0,04 \\
\hline Bombacaceae & 2 & 1 & 0,89 \\
\hline Boraginaceae & 1 & 1 & 0,01 \\
\hline Burseraceae & 2 & 1 & 0,09 \\
\hline Caesalpiniaceae & 7 & 3 & 0,45 \\
\hline Cecropiaceae & 7 & 1 & 0,21 \\
\hline Euphorbiaceae & 4 & 2 & 0,72 \\
\hline Fabaceae & 10 & 4 & 2,89 \\
\hline Flacourtiaceae & 1 & 1 & 0,03 \\
\hline Lauraceae & 12 & 2 & 1,77 \\
\hline Lecythidaceae & 3 & 2 & 1,20 \\
\hline Meliaceae & 7 & 1 & 2,19 \\
\hline Mimosaceae & 29 & 3 & 3,00 \\
\hline Moraceae & 14 & 5 & 2,68 \\
\hline Myristicaceae & 1 & 1 & 0,11 \\
\hline Nyctaginaceae & 1 & 1 & 0,07 \\
\hline Phytolaccaceae & 5 & 1 & 0,07 \\
\hline Rhamnaceae & 1 & 1 & 0,01 \\
\hline Rubiaceae & 1 & 1 & 0,01 \\
\hline Solanaceae & 1 & 1 & 0,01 \\
\hline Sterculiaceae & 2 & 1 & 0,01 \\
\hline Ulmaceae & 6 & 1 & 0,06 \\
\hline Total & 138 & 41 & 20,03 \\
\hline
\end{tabular}

$\mathrm{cm}$. A altura variou de $4,5 \mathrm{~m}$ a $39,4 \mathrm{~m}$ com média de $15,9 \mathrm{~m}$, sendo que $67,4 \%$ dos indivíduos apresentou menos de 20,0 m de altura. A maior altura foi apresentada por um indivíduo da espécie Cedrela odorata e o maior diâmetro foi da espécie Nectandra sp. As distribuições de indivíduos por classe de diâmetro e altura encontradas neste trabalho (Fig. 2 e 3 ) e no de Hummel (1995) foram significativamente diferentes entre si (Tab. 3). A área estudada por Hummel (1995) apresentou árvores de maior tamanho, com diâmetro máximo de $235 \mathrm{~cm}$ e altura média de 19,5 m e máxima de 41,7 m. No trabalho de Alves (1990), utilizando um DAP mínimo de $10 \mathrm{~cm}$, a altura média das árvores em áreas de cabruca variou de $16,4 \mathrm{~m}$ a 21,4 m, com média geral de $18,9 \mathrm{~m}$.

Esses dados mostram que o tamanho médio das árvores varia muito entre as áreas de cabruca. Essas variações podem ser explicadas por diferenças no histórico de implantação e manejo das áreas estudadas. Diferenças no critério de seleção das árvores e na idade da cabruca podem determinar grandes variações na estrutura da vegetação. Diferenças nas propriedades do solo e nas características da floresta original também podem ter influência.

O número de indivíduos por parcela de $20 \mathrm{~m}$ x $25 \mathrm{~m}$ variou de 0 a 11 , com média de 2,7 ind/ $500 \mathrm{~m}^{2}$ e desvio padrão de 2,4 . A razão variância/média foi 2,1 , mostrando uma tendência a distribuição espacial agregada. Houveram três parcelas com número de indivíduos muito maior do que a média das demais. Isto ocorreu porque essas parcelas se encontravam sobre uma mancha de solo muito raso com afloramentos de rocha, onde o cacau quase não sobrevive. Por essa razão, foi deixado um número maior de árvores nesse local.

Excluindo-se essas três parcelas, o número de indivíduos variou de 0 a 5 , com média de $2,2 \mathrm{ind} / 500 \mathrm{~m}^{2}$, desvio padrão de 1,5 e razão variância/média de 1,1, mostrando uma tendência a um padrão de distribuição espacial aleatório. Entre os fatores que podem ter influência direta sobre esse padrão temos: a disposição dos indivíduos na floresta original, o modo como foi feito o raleamento e a maneira como ocorre a regeneração e substi- 


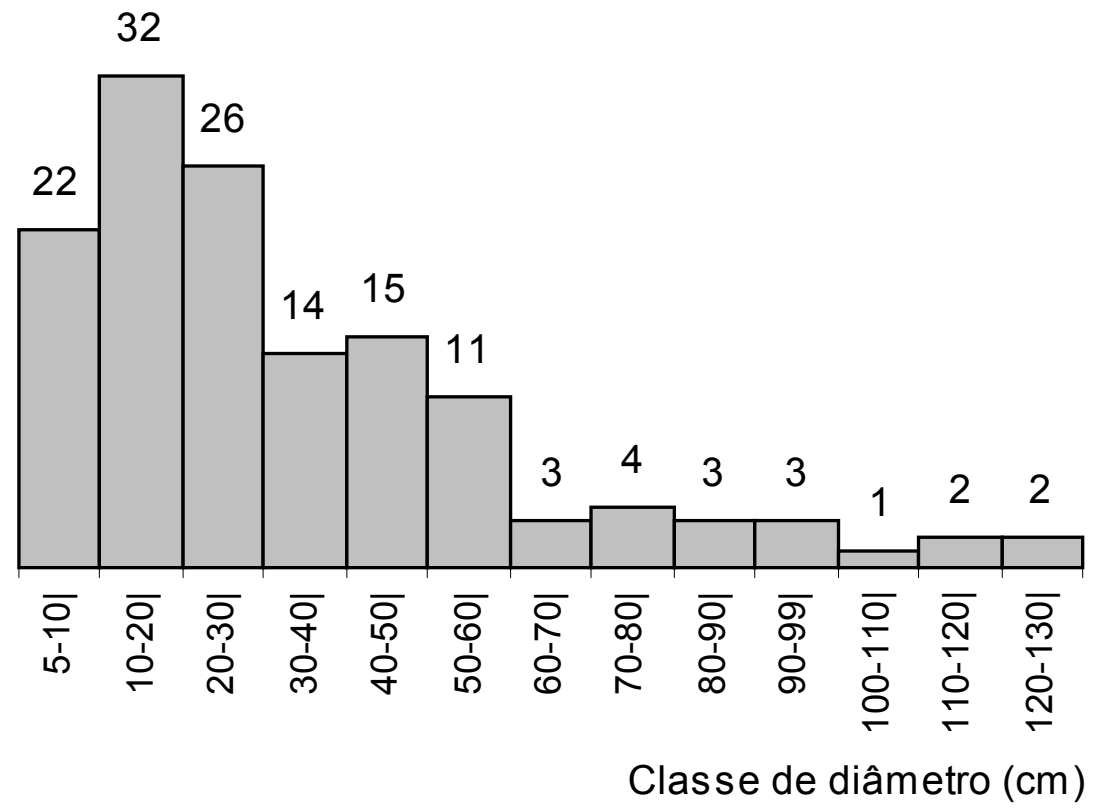

Figura 2. Distribuição de número de indivíduos por classe de diâmetro (DAP), para árvores encontradas em 2,6 ha de cabruca.

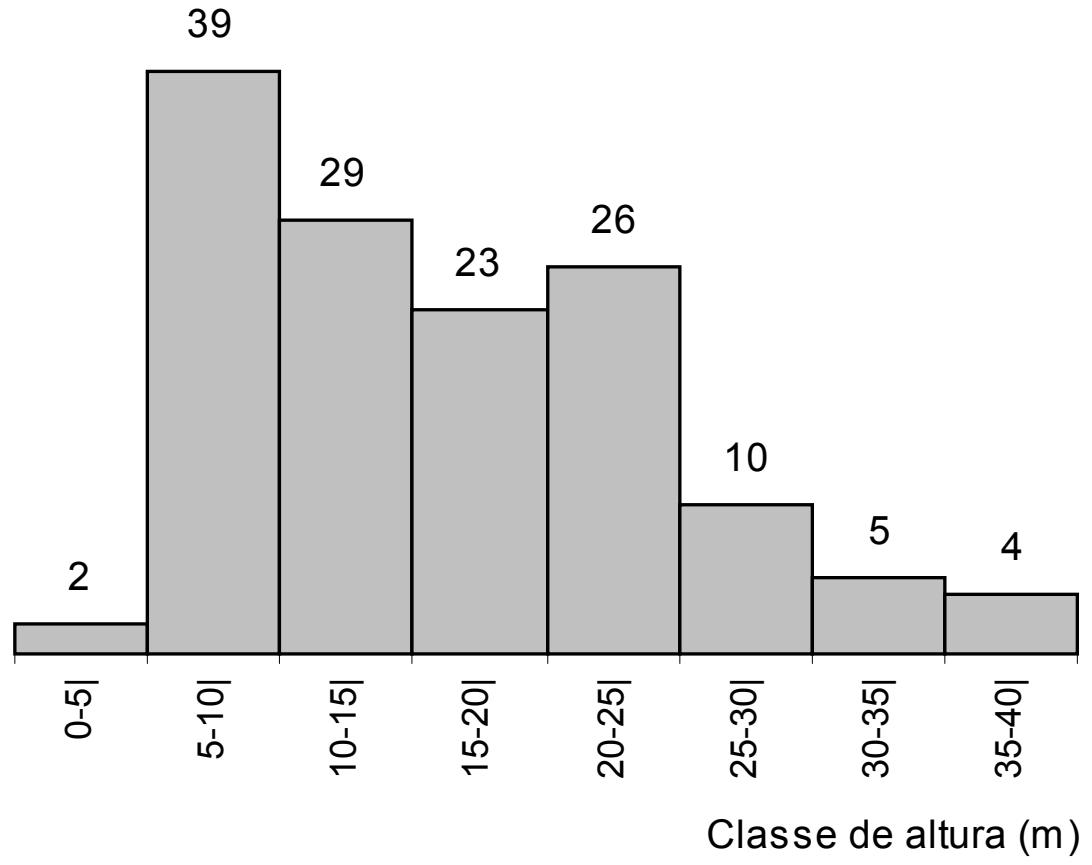

Figura 3. Distribuição de número de indivíduos por classe de altura, para árvores encontradas em 2,6 ha de cabruca. 
Tabela 3. Resultado do teste Kolmogorov-Smirnov na comparação das distribuições de frequências de número de indivíduos arbóreos por classe de altura e diâmetro de duas áreas de cabruca na região sul da Bahia.

\begin{tabular}{ll|c|c|c|c|c}
\hline & \multicolumn{2}{c|}{$\mathrm{N}^{0}$ de indivíduos } & \multicolumn{2}{c|}{ Valor } & \multirow{2}{*}{ Significância } & a \\
\cline { 2 - 5 } & área 1 & área 2* & calculado & tabelado & & \\
\hline Classe de altura & 138 & 145 & 0,169 & 0,162 & Sign. diferentes & 0,05 \\
\hline Classe de diâmetro & 138 & 145 & 0,233 & 0,194 & Sign. diferentes & 0,01 \\
\hline
\end{tabular}

* Hummel (1995)

tuição das árvores. Quanto mais antiga a cabruca, maior a influência deste último fator em relação aos primeiros. Os resultados mostram que os métodos de raleamento e regeneração não conseguiram dar à vegetação estudada um padrão uniforme como seria esperado para uma área de cultivo agrícola. Isso mostra a influência de fatores naturais como dispersão de sementes, diferenças de solo e relevo e mortalidade agindo sobre a distribuição espacial dos indivíduos e espécies na dinâmica da vegetação.

Mostra também que o critério utilizado para seleção das árvores, tanto na implantação como na regeneração, prioriza a espécie da árvore em relação ao seu posicionamento espacial, ou seja, o indivíduo de uma espécie desejável em uma posição irregular é preferido em relação a um de outra espécie em posição mais regular.

As cabrucas e as florestas primárias apresentam grandes diferenças estruturais entre si. Em um levantamento realizado em 1 ha de floresta nativa na região de Serra Grande, Uruçuca, BA, utilizando o limite mínimo de $5 \mathrm{~cm}$ de DAP, Thomas et al. (in press) encontraram 2.450 indivíduos e 458 espécies arbóreas. Alves (1990) encontrou, para árvores acima de $10 \mathrm{~cm}$ de DAP, uma densidade que variou de 35 a 133 ind/ha, com média de 63 ind/ ha em áreas de cabruca; e 596 a 830 ind/ha, com média de 700 ind/ha, em áreas de flores- ta nativa; concluindo que as cabrucas apresentam menos de $10 \%$ da quantidade de árvores da mata nativa.

Apesar da baixa densidade de árvores, as cabrucas são difíceis de serem diferenciadas das florestas nativas através de fotos aéreas e de satélites devido à presença dos cacaueiros que ocupam $\mathrm{e}$ fecham por baixo os espaços entre as copas das árvores de sombra. (Saatchi et al. 2001). Alvim \& Pereira (1965) estimaram uma média de 724 cacaueiros/ha nas cabrucas, enquanto Alves (1990) estimou uma média de 822 cacaueiros/ha.

Diversidade de espécies e similaridade florística - o índice de diversidade de Shannon foi 3,35, tanto para número de indivíduos como para importância. O índice de Brillouin foi 2,96. O primeiro índice foi calculado para fins de comparação, pois é o mais utilizado em trabalhos fitossociológicos. O segundo é o mais adequado para medir a diversidade de uma coleção completamente recenseada ou uma amostra não aleatória (Pielou 1977). As oito espécies mais importantes responderam por $50,8 \%$ do total de importância. Foram encontradas 14 espécies com apenas um indivíduo na área estudada. Isso mostra que a vegetação estudada, apesar de apresentar baixa densidade de indivíduos e forte influência antrópica, apresenta uma alta diversidade de espécies, refletindo assim a alta diversidade biológica natural da região. 
A curva de aumento de número de espécies com o aumento da área amostrada (Fig. 4) não mostrou sinal de estabilização com 52 parcelas de $20 \mathrm{~m} \times 25 \mathrm{~m}$ (2,6 ha). A forma da curva, porém, sofreu grande influência da sequência em que as parcelas foram adicionadas, pois a riqueza florística foi muito variável entre as parcelas. ' O número de espécies por parcela variou de 0 a 10 , com média de 2,4 esp. $/ 500 \mathrm{~m}^{2}$ e desvio padrão de 2,2, havendo três parcelas com uma concentração de espécies muito maior que as demais.

De acordo com a posição dessas parcelas na sequência, houve uma alteração na forma da curva. Esses dados mostram que o tamanho de parcela utilizado para fazer a curva e o tamanho da área amostral total foram insuficientes para serem representativos da composição florística da cabruca estudada. Mesmo assim, os resultados obtidos, ao serem comparados com estudos realizados em outras áreas de cabruca, ressalvadas as diferenças de metodologia utilizada em cada caso, permitem visualizar as características gerais da comunidade arbórea das cabrucas.

No trabalho de Hummel (1995), foi encontrada uma diversidade de 3,06 (Shannon), portanto, também alta, embora seja menor do que a observada no presente levantamento. Comparando as espécies identificadas neste trabalho com as do de Hummel (1995), encontramos 22 espécies em comum.

A similaridade entre as áreas foi de 54,3\% (Sorensen) e 47,3\% (Bray-Curtis). Sendo que as duas áreas são relativamente próximas, com condições edafoclimáticas semelhantes, poderiam ter apresentado maior similaridade florística. Isto certamente não aconteceu devido ao pequeno número de indivíduos amostrados, os quais pertencem somente a uma pequena parte do total de espécies que ocorrem nas cabrucas estudadas.

$\mathrm{Na}$ lista das principais espécies que ocorrem em áreas de cabruca apresentada por Alvim \& Pereira (1965) aparecem 24 espécies, enquanto Vinha \& Silva (1982) descreveram 131 espécies que ocorrem nas cabrucas. Verificamos

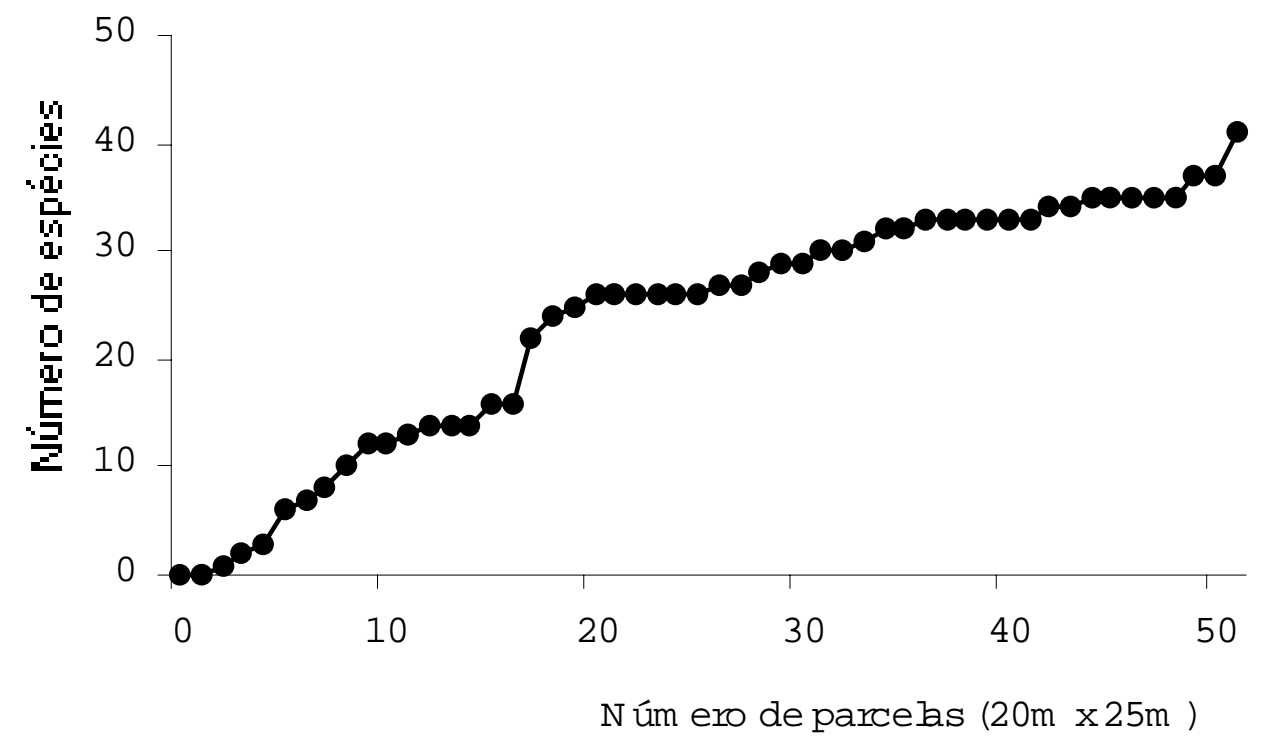

Figura 4. Aumento do número de espécies arbóreas com o aumento da área amostrada em uma área de cabruca. 
que em cada um desses trabalhos ocorrem espécies que não aparecem em nenhum dos outros, mostrando que existe uma grande variedade de espécies ocorrendo nas cabrucas.

A região de ocorrência das cabrucas apresenta diversidade de solo e relevo e um gradiente climático, indicando que deve existir também uma heterogeneidade florística entre as áreas de cabruca, com espécies que ocorrem só em alguns locais, ou que ocorrem mais em um local do que em outro, como seria esperado em áreas de mata nativa.

Caracterização das espécies - além de apresentar um menor número de espécies que as áreas de floresta nativa, a área de cabruca estudada apresentou invasão de espécies pioneiras, secundárias e exóticas. Entre as 41 espécies encontradas, 24 são naturais das florestas primárias da região. A maioria dessas espécies (18) ocorreu com apenas um ou dois indivíduos na área, o que pode ser reflexo da baixa densidade natural dessas espécies na floresta. Os indivíduos de maior porte podem ser ainda remanescentes da floresta original. Algumas espécies, porém, apresentam indivíduos jovens, mostrando que conseguem se reproduzir na cabruca.

Espécies como Cedrela odorata e Nectan$d r a$ sp. parecem até ser favorecidas na cabruca, ocorrendo em uma densidade maior do que a que ocorrem em mata nativa. Nos levantamentos realizados em floresta primária por Mori et al (1983) e Thomas et al. (in press), elas não aparecem, enquanto no presente trabalho e no realizado por Hummel (1995) em cabruca elas aparecem com uma importância relativamente alta. Foi observado durante a coleta dos dados um grande número de plântulas dessas espécies na área estudada e algumas árvores jovens, poupadas do corte pelos trabalhadores rurais por sua madeira de boa qualidade.

Outras espécies de madeira nobre como $\mathrm{Ca}$ riniana estrellensis e Cariniana legalis também não aparecem nos levantamentos de floresta realizados por Mori et al (1983) e Thomas et al. (in press). São espécies muito comuns em áreas de cabruca, embora não apresentem alta densidade.

Foram encontradas 11 espécies nativas características de clareiras e florestas secundárias. A maioria delas (7) ocorreu com três ou mais indivíduos na área. Espécies como Pithecelobium polycephalum, Cecropia sp. e Trema micrantha apresentam a vantagem de ter alta fecundidade e crescimento rápido, mas são normalmente cortadas durante o manejo por não ter madeira de boa qualidade. Ocorreram em maior quantidade devido ao estado de abandono em que se encontrava a área na época da medição, permitindo que essas espécies atingissem o tamanho mínimo para entrar na contagem.

Ocorreram na área algumas espécies frutíferas consumidas pelo homem. Spondias lutea (cajazeira), que foi a espécie mais importante na área estudada, foi a segunda espécie em importância no levantamento de Hummel (1995) e a espécie de maior densidade no trabalho de Alvin \& Pereira (1965). Artocarpus heterophyllus (jaqueira) foi a espécie mais importante no levantamento realizado por Hummel (1995) e a terceira em densidade no levantamento de Alvim \& Pereira (1965). É uma espécie introduzida que atualmente cresce de forma espontânea nas cabrucas. São espécies que apresentam boa regeneração natural, sendo muitas vezes poupadas do corte por seu valor nutritivo. Outras espécies frutíferas encontradas foram Persea americana (abacateiro) e Rollinia mucosa (pinha). A proximidade com a sede da fazenda favoreceu o aparecimento dessas espécies, as quais são cultivadas no pomar doméstico da fazenda e suas sementes podem ter sido dispersadas por animais ou pelo homem para a cabruca.

Outras espécies exóticas à região são Erythrina fusca e Cola acuminata, as quais foram introduzidas para sombrear o cacau. 
$\mathrm{Na}$ área estudada por Hummel (1995), as espécies exóticas apresentaram maior importância do que no presente trabalho. A importância das espécies exóticas está relacionada com o histórico de manejo das áreas.

Considerações sobre o manejo e informações sobre o histórico de manejo da área estudada ajudam a explicar melhor os resultados obtidos. Devido a uma recomendação da CEPLAC para que fosse reduzida a quantidade de sombra nas culturas, durante anos as áreas da fazenda foram deixadas tornar-se propositadamente mais abertas, evitando-se o plantio e inibindo-se a regeneração natural das árvores.

Este fato explica a baixa densidade de indivíduos grandes na área.

Posteriormente, os cacaueiros começaram a sentir o excesso de exposição ao sol, e os trabalhadores passaram a deixar algumas árvores crescer para aumentar o sombreamento. Esse fato, aliado à baixa frequência de roçagem nos últimos anos, explicam a alta porcentagem de indivíduos jovens encontrada na área.

As cabrucas são na realidade áreas de cultivo manejadas e a forma de manejo exerce uma influência direta sobre a estrutura e composição florística do componente arbóreo dessas áreas.

Nas plantações de cacau em geral, o homem pode matar algumas árvores que considerar indesejáveis devido ao excesso de sombra na cultura ou por outras razões (tradicionalmente, as árvores não eram derrubadas para utilização da madeira, com a crise econômica, porém, essa prática vem sendo feita em muitas fazendas). Pode também plantar árvores, como Erythrina spp. e Artocarpus heterophyllus, por exemplo, em áreas onde existe pouco sombreamento.

A principal forma de manejo nas cabrucas é o controle da regeneração natural das árvores através da roçagem periódica da vegetação rasteira. Com o passar dos anos, as árvores origi- nais da mata vão morrendo, derrubadas pelo vento ou por outras causas, e precisam ser substituídas. Nesse processo, algumas espécies entre as que estão regenerando são poupadas do corte para crescer e ocupar os espaços abertos.

As espécies que se reproduzem bem nas cabrucas e apresentam crescimento rápido certamente levam vantagem. Existe porém uma seleção das espécies poupadas, seja por serem frutíferas, por apresentarem madeira de boa qualidade ou por outras razões.

Portanto, as cabrucas vão se tornando com passar do tempo cada vez mais diferentes em composição e estrutura das matas originais. Mesmo assim, a grande diversidade de espécies e heterogeneidade encontradas em áreas de cabruca continuam sendo um reflexo da diversidade e heterogeneidade natural das florestas da região.

Importância das cabrucas para a conservação ambiental - as cabrucas não devem ser consideradas apenas como mais um sistema agrícola, pois a sua importância para a conservação ambiental é muito grande na região sul da Bahia. Além de sua importância para a conservação do solo e do clima, o seu papel na conservação da biodiversidade é fundamental. É certo que as cabrucas não devem de forma alguma substituir as áreas de Reserva Legal ou as Áreas de Preservação Permanente das propriedades agrícolas. Pelo contrário, algumas áreas de cabruca devem ser transformadas em áreas de preservação através do abandono da cultura e regeneração natural ou enriquecida da floresta.

As áreas de reserva de floresta são muito poucas e não contemplam a diversidade de solo e relevo da região. Não existe atualmente uma única área de floresta primária conservada sobre os solos mais férteis. As áreas de Reserva Legal e os pequenos fragmentos de floresta conservados nas fazendas sempre são sobre manchas solo mais pobre, ou sobre afloramentos de 
rochas ou com outros impedimentos pelos quais o cacau não sobreviveu.

Muitas espécies de madeira nobre tem hoje ainda o maior seu banco genético nas áreas de cabruca, pois nas áreas de floresta já foram praticamente exterminadas pelo corte seletivo. Muitas espécies da flora, principalmente epífitas, e da fauna, incluindo aves e mamíferos, utilizam as cabrucas não apenas como corredores biológicos, mas como seu habitat, onde vivem e se reproduzem naturalmente.

Vários estudos ainda não publicados vem comprovando essas afirmações e mostrando a importância biológica dessas áreas, atualmente gravemente ameaçadas de serem desmatadas devido à crise na cultura do cacau.

\section{Agradecimentos}

Agradeço à Universidade Estadual de Santa Cruz pelo apoio financeiro e material ao trabalho; a J. G. Jardim, do herbário da CEPLAC, pelo auxílio na coleta e identificação do material botânico e aos estudantes D. Átila, M. A. O. Lima e M. S. Santos pela participação na coleta de dados.

\section{Referências Bibliográficas}

Alger, K. ; Caldas, M. 1996. Cacau na Bahia. Ciência Hoje 117: 28-35.

Alves, M. C. 1990. The role of cacao plantations in the conservation of the Atlantic Forest of southern Bahia, Brazil. Masters Thesis, University of Florida.

Alvim, P. de T. 1966. O problema do sombreamento do cacaueiro. Cacau Atualidades 3 (2):2-5.

Alvim, P. de T.; Pereira, C. .P. 1965. Sombra e espaçamento nas plantações de cacau no Estado da Bahia e Centro de Pesquisas do Cacau, Itabuna, Bahia, Brasil. Pp.18-19. In: Relatório Anual do CEPEC 1964. CEPLAC,. Ilhéus.
Franco, M.; Holz, B.; Kaule, G.; Kleyer, M.; Menezes, M. de; Pereira, J. M.; Trevisan, S. 1994. Program of the Enviromental Development of the Rainforest Region in Bahia, Brazil Development of a Methodology. Institut für Landschaftsplanung und Ökologie, Universität Stuttgart.

Greig-Smith, P. 1983. Quantitative plant ecology. Blackwell Scientific Publication. Oxford.

Hummel, M. 1995. Botanical analysis of the shade tree population in two cabruca cocoa plantations in southern Bahia, Brazil. Thesis for the Diploma in Agricultural Biology, University of Stuttgart.

Mueller-Dumbois, D.; Ellenberg, H. 1974. Aims and metods of vegetation ecology. John Wiley. New York.

Mori, S. A.; Boom, B. M.; Carvalho, A. M. de; Santos, T. S. 1983. Southern bahian moist forests. Botanical Review 49(2):155-232.

Pielou, E. C. 1997. Mathematical Ecology. John Wiley \& Sons. New York.

Por, F. D. 1992. Sooretama: the atlantic rain forest of Brasil. Den Haag, SPB Academic Publishing, $230 \mathrm{p}$.

Rice, R. A. \& Greenberg, R. 2000. Cacao Cultivation and the Conservation of Biological Diversity. Ambio 29(3): 167- 173.

Saatchi, S.; Agosti, D.; Alger, K.; Delabie J.; Musinsky J. 2001. Examining fragmentation and loss of primary forest in the Southern Bahian Atlantic Forest of Brazil with radar imagery. Conservation Biology 15(4): 867-875.

Siegel, S. 1975. Estatística não-paramétrica. McGraw-Hill. São Paulo.

Thomas, W. W.; Carvalho, A. M. de; Amorim, A. M. A.; Garrison, J.; Arbeláez, A. L. 1998. Plant endemism in two forests in southern Bahia, Brasil. Biodiversity and Conservation 7: 311-322.

Thomas, W.W.; Carvalho, A.M. de; Amorim, A.M.; Garrison, J.; Santos, T.S. dos. In press. Diversity of woody plants in the Atlantic forest of Southern Bahia, Brazil. Biotropica.

Vinha, S. G. da; Silva, L. A. M. 1982. Árvores aproveitadas como sombreadoras de cacaueiros no sul da Bahia e norte do Espírito Santo. CEPLAC. Ilhéus. 
